\title{
INFLUENCE OF THE CUTTING EDGE ANGLE OF THE GRANULATOR ON THE EXTRUSION PROCESS AND PELLETS PROPERTIES
}

\author{
Janusz W. Sikora ${ }^{1}$, Oleh Suberlyak ${ }^{2}$, Ludmila Dulebová ${ }^{3}$ \\ ${ }^{1}$ Lublin University of Technology, 36 Nadbystrzycka Str., 20-618 Lublin, Poland \\ janusz.sikora@pollub.pl \\ ${ }^{2}$ L'viv Polytechnic National University, 12 Bandery Str., 79-013 Lviv, Ukraine \\ suberlak@polynet.lviv.ua \\ ${ }^{3}$ Technical University of Košice, 9 Letná Str., 042-00 Košice, Slovakia \\ ludmila.dulebova@tuke.sk
}

Keywords: hot granulation, low-density polyethylene, cutting edge angle, extrusion

\begin{abstract}
This paper is concerned with experimental tests of the process of extrusion with hot granulating of polymer, conducted to determine the influence of a change in the value of the cutting edge angle of a granulator knife on the basic parameters of the obtained pellets and on the process of extrusion with granulation. The available literature does not raise this issue. In the present study, the process of extrusion with hot granulation was studied with the use of low-density polyethylene.
\end{abstract}

\section{INTRODUCTION}

Pellets are obtained in the process of cold granulation in the solid state and hot granulation in the plastic state. Granulation can also be divided into primary granulation, occurring during the process of production of a polymer, and secondary granulation, which takes place during the utilization of polymers in the process of recycling [1, 2].

Granulation is a polymer machining method, fully complementary to processing, without which it would be impossible to obtain polymer products of required quality, ready to use under given conditions $[3,4]$. Pellets are also the basic material to be modified by different additives e.g. foaming agent [5].

Granulators for hot granulation are structurally connected with extrusion heads and are designed in various ways. A granulating extrusion head is mounted to the barrel of a single- or a twin-screw extruder and can have different constructional designs. The extruder head sometimes requires independent support due to its considerable mass and small yet still unavoidable vibrations $[6,7]$.

Cold granulation consists in the extrusion of polymer in the form of rods with a diameter of $3-5 \mathrm{~mm}$, their subsequent cooling, and final cutting into small segments (pellets). In this case, straight heads, from the point of view of the direction of flow of polymer in the head, are usually used, with dies having several to several dozen openings. These heads are not structurally or technologically complex and do not have to meet particularly high requirements. However, granulator's knives should be made from the best steel e.g. the one used for injection molds and other processing tools $[8,9]$. 
Heads for hot granulation are characterized by more complex design. The complication of the design follows from the fact that granulation is performed directly after the polymer leaves the head, when it is still in the plastic state.

\section{EXPERIMENTIAL}

The aim of the experimental tests presented in this paper was to determine the design effectiveness of the granulation process by performing autothermal extrusion with hot granulation of polyethylene using different knives with diverse cutting edge angles.

\subsection{Material}

Tests were conducted using a low-density polyethylene manufactured by Basell Orlen Polyolefins under the trade name Malen E, symbol FABS, 23-D022. This polymer is characterized by satisfactory strength parameters and very advantageous optical properties and is also notable for its high transparency and gloss.

Malen E, FABS 23-D022 contains an antioxidant as well as slip and anti-blocking additives. The basic properties of this polymer are shown in Table 1.

Table 1: Selected properties of polyethylene, Malen E, FABS 23 - D022

\begin{tabular}{|l|c|}
\hline \multicolumn{1}{|c|}{ Property } & Value \\
\hline Density, $\mathrm{kg} / \mathrm{m}^{3}$ & $919 \div 923$ \\
\hline Melt flow rate, $\mathrm{g} / 10 \mathrm{~min}\left(230^{\circ} \mathrm{C} / 2.16 \mathrm{~kg}\right)$ & $1.6 \div 2.5$ \\
\hline Tensile strength at break, $\mathrm{MPa}$ & 11 \\
\hline Vicat softening temperature $\mathrm{A} / 50,{ }^{\circ} \mathrm{C}$ & 90 \\
\hline Elongation at break, $\%$ & 600 \\
\hline Swell effect & max. 160 \\
\hline
\end{tabular}

\subsection{Experiment Outline}

The following test factors were adopted in the experimental design:

- polymer flow rate in the extruder's plasticizing system, $\mathrm{kg} / \mathrm{h}$,

- $\quad$ total power consumed by the extruder with a granulator and a cooling unit, W,

- total power transmitted by the polymer during the process of extrusion with a hot granulation, $\mathrm{W}$,

- $\quad$ unit consumption of total energy consumed by the extruder with a granulator and a cooling unit $\mathrm{E}_{\mathrm{JC}}, \mathrm{J} / \mathrm{g}$,

- $\quad$ energy efficiency of the extruder with a granulator and a cooling unit, \%,

- bulk density of the obtained pellets, $\mathrm{kg} / \mathrm{m}^{3}$,

- $\quad$ angle of natural repose of pellets, deg,

- $\quad$ screw speed $60 \mathrm{rev} / \mathrm{min}$.

The variable factor was the cutting edge angle of the granulator knife set in the tool's system: $\beta_{1}=20^{\circ}, \beta_{2}=25^{\circ}, \beta_{3}=30^{\circ}, \beta_{4}=35^{\circ}, \beta_{5}=40^{\circ}$ (Fig. 1 ). 


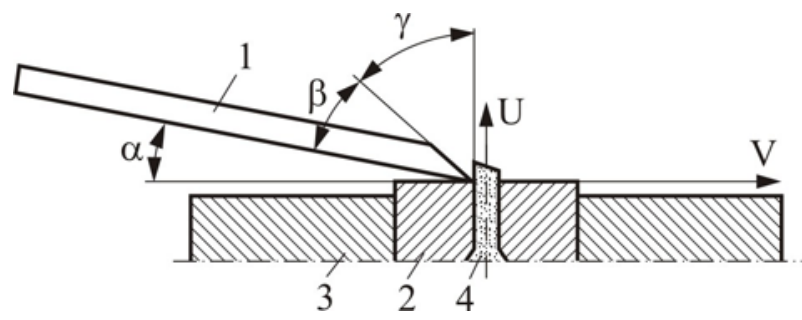

Figure 1: Angles characterising the cutting knife and its position in relation to processed polymer: $V$ - speed of the knife, $U$-extrudate rate, $a$-clearance angle, $b$-cutting edge angle, $g$ - rake angle, 1 - knife, 2 -die, 3 - head, 4 - extrudate

\section{RESULTS}

The results obtained during the extrusion with hot granulation of low density polyethylene are shown in Table 2 and Fig. 2.

Table 2: Results for factors tested indirectly

\begin{tabular}{|l|c|c|c|c|c|}
\hline \multirow{2}{*}{ Test factors } & \multicolumn{4}{|c|}{ Cutting edge angle } \\
\cline { 2 - 5 } & $\mathbf{2 0}$ & $\mathbf{2 5}$ & $\mathbf{3 0}$ & $\mathbf{3 5}$ & $\mathbf{4 0}$ \\
\hline Polymer flow rate, $\mathrm{kg} / \mathrm{h}$ & \multicolumn{4}{|c|}{3,89} \\
\hline Total power consumed by the extruder, $\mathrm{W}$ & \multicolumn{4}{|c|}{1744,8} \\
\hline Power transmitted by the polymer, $\mathrm{W}$, & \multicolumn{4}{|c|}{1174,3} \\
\hline Unit consumption of total energy $\mathrm{E}_{\mathrm{JC}}, \mathrm{J} / \mathrm{g}$ & \multicolumn{4}{|c}{1615,5} \\
\hline Energy efficiency of extrusion process, \% & \multicolumn{4}{c}{67,3} \\
\hline
\end{tabular}

a)

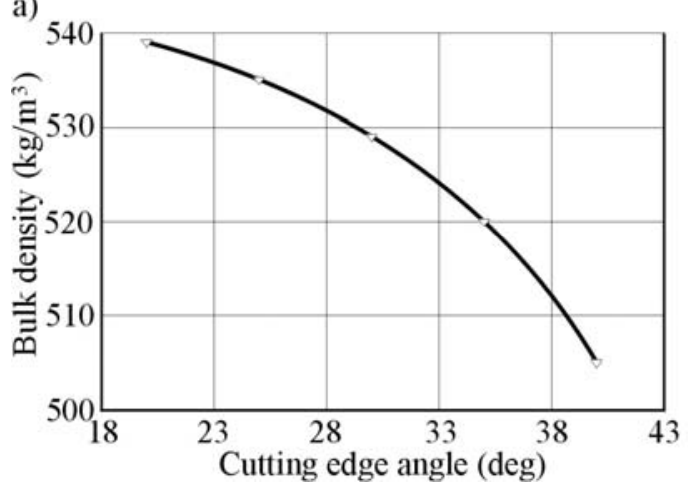

b)

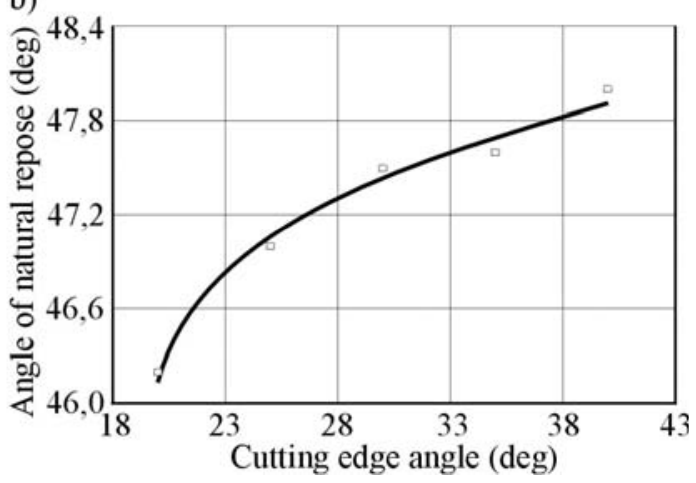

Figure 2: Relationship between a) bulk pellet density and b) angle of natural repose and the cutting edge angle of the granulator knife

\section{CONCLUSION}

It follows from the present studies that it is more advantageous to use smaller cutting edge angles. The shapes and dimensions of pellets obtained using smaller angles allow one to achieve better bulk densities and better angle of natural repose for pellets, and, as a consequence, a product of a better quality. 
To a certain degree, the cutting edge angle of granulator knives can be a design factor, the change of which may affect the shape and dimensions of pellets and thus the effectiveness of hot granulation.

On the other hand, however, smaller cutting edge angles of knives cause lower knife durability. Further studies are then needed to unequivocally solve this problem. Especially that it may turn out that merely slightly higher quality of pellets will necessitate more frequent replacement of faster-wearing knives.

\section{REFERENCES}

[1] Sikora J.W.: Screw extrusion. Chaper 5 in Sabu T. i Yang W. "Advances in Polymer Processing: From macro- to nano- scales". Woodhead Publishing. Oxford - Cambridge New Delhi 2009.

[2] Sikora R.: Obróbka tworzyw wielkocząsteczkowych. Wydawnictwo Edukacyjne, Warszawa 1996.

[3] Tor-Świątek Aneta: Evaluation of the effectiveness of the microcellular extrusion process of low density polyethylene. Eksploatacja i niezawodność. Maintenance and Reliability 2013, $3, \mathbf{1 5}, 225-229$.

[4] Garbacz T.: Structure and properties of cellular thin-walled cable coatings. Polimery 2012, 11/12, 57, $865-868$.

[5] Sasimowski E.: Studies in the effectiveness of a new generation extruder. Part I. The influence of the location of the rotating sleeve of the barrel in the plasticizing system. Polimery 2011, 5, 56, $390-396$.

[6] Samujło B, Sikora J. W.: The impact of selected granulometric properties of poly(vinyl chloride) on the effectiveness of the extrusion process. Journal of Polymer Engineering 2013, 1, 33, 77-85.

[7] Dulebová L., Greškovič F., Spišák E., Duleba B.: Tool steels for injection forms and adhesive wearing of selected tool steel. Technological and design aspects of extrusion and injection moulding of thermoplastic polymer composites and nanocomposites. Lviv Polytechnic Publishing House. Lviv 2013.

[8] Greškovič F., Dulebová L., Spišák E., Duleba B., Varga J.: Teoria i praktyka. Tribologia 2013, 1, 44, 47 - 58. 